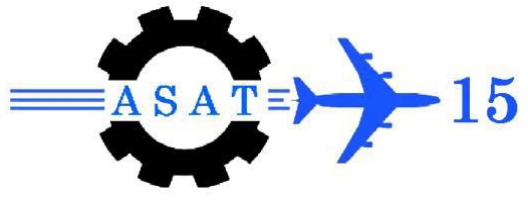

\title{
Thermal Characteristics of a Dual Swirl Vanes Co-Axial Burner
}

\author{
J. Soliman ${ }^{*}$, A. Emara ${ }^{\dagger}$, and A. Hussien ${ }^{\ddagger}$
}

\begin{abstract}
The present work aims to clarify the stability limits and thermal combustion characteristics of a dual swirl vanes co-axial burner. The investigated burner consists of eight gaseous jets arranged in two consecutively interacted equal lotus bundles in the axial direction downstream of the flow. These eight jets can be easily moved and directed to penetrate the combustion reaction zone at different axial positions with four inclination angles at the burner axis $\left(\theta=0^{\circ}, 30^{\circ}, 45^{\circ}\right.$, and $\left.60^{\circ}\right)$. This axial motion is easily performed by adjusting few screws mounted on the burner which facilitate the jet interaction inside the surrounded combustion air between the liquid and gas fuels which consumed by the dual burner.
\end{abstract}

At different jet injection positions and jet inclination angles, stability loop, temperature, and regulated gas emissions such as nitrogen oxides, carbon monoxide and unburned hydrocarbons are measured.

The location of interaction has an influence on the pollutant emissions and temperature as well as the combustion efficiency. This influence will be clearly demonstrated to reach the optimum design configuration.

Keywords: Dual fuel burners, jet slope angle, flame stability.

\section{Nomenclature}

$\begin{array}{ll}\mathrm{A} / \mathrm{F} & \text { Air-fuel ratio } \\ \mathrm{CO}_{2} & \text { Carbon Dioxide } \\ \mathrm{D} & \text { Combustion chamber inner diameter } \\ \mathrm{T}_{\mathrm{ex}} & \text { Exhaust gas temperature } \\ \mathrm{X}_{\mathrm{inj}} & \text { Gaseous fuel injection location } \\ \mathrm{T} & \text { Hot gases } \\ \theta & \text { Jet finger injection angle } \\ \mathrm{LPG} & \text { Liquefied Petroleum Gas } \\ \mathrm{NO}_{\mathrm{X}} & \text { Nitrogen oxides } \\ \mathrm{ppm} & \text { Part per million } \\ \mathrm{X}_{\mathrm{a}} & \text { The axial distance of measuring } \\ \mathrm{C}_{\mathrm{X}} \mathrm{H}_{\mathrm{X}} & \text { Unburned hydrocarbons }\end{array}$

* Demonstrator, Dept. of Mechanical Power Engineering, Faculty of Engineering, Mataria, Helwan University, Cairo, Egypt, joe2adel@yahoo.com

$\dagger$ Assistant Professor, Dept. of Mechanical Power Engineering, Faculty of Engineering Mataria, Helwan University, Egypt., aarazek@yahoo.com

$\$$ Assistant Professor, Dept. of Mechanical Power Engineering, Faculty of Engineering Mataria, Helwan University, Egypt. 


\section{Introduction}

The demand for gas turbine engines with reduced emission levels, stable combustion conditions and low specific fuel consumption is the goal at the past two decades to perform an efficient combustion. Gas turbine manufacturers have developed and continue to enhance lean combustion systems to comply with emissions regulations for nitrogen oxides, carbon monoxide, and unburned hydrocarbons. In a combustor under fuel-lean conditions, achieving stable combustion requires overcoming several inter-related problems such as flame stabilization, flame stability and extinction, and combustion oscillations or thermoacoustic instabilities which depend on the boundary conditions of the engine.

The present work inspects new designs used to achieve these goals of emissions reduction at stable combustion conditions [1].

Combustion characteristics and aerodynamics for different liquid fuels are important to be investigated in the tuning of the new burners.

Fluid flow and combustion characteristics of co-flowing LPG and kerosene in a cylindrical water cooled combustion chamber have been investigated experimentally. Effect of injection location and percentage of injected liquid fuel on fluid flow and combustion characteristics was investigated. The location of liquid fuel injection is changed axially far from the burner exit and the length of the flame is shortened.

Value of temperature is increased in some sections of the combustion chamber and is decreased in some other sections compared to the case of LPG alone depending on the percentage and location of injection of liquid fuel. Values of temperature decrease with increase in percentage of injected kerosene due to incomplete combustion with increase in liquid mass flow rate. The flame stability is improved as a result of liquid fuel injection. [2].

The aerodynamic structure of the flame close to the burner determines to a large extent the structure of the flame as a whole and the formation of $\mathrm{NO}_{\mathrm{x}}$. Therefore, controlling the aerodynamics close to the burner means controlling the $\mathrm{NO}_{\mathrm{x}}$-formation. From the low $\mathrm{NO}_{\mathrm{x}}$ flame it was observed visually and experimentally from concentration measurements of fuel species $\left(\mathrm{CH}_{4}, \mathrm{C}_{2} \mathrm{H}_{6}\right)$ and the calculation of the richness that the fuel jets did not mix very rapidly, inducing a kind of fuel staging. For this specific type of gas spud burner, fuel staging can easily be realized by creating a "finger flame", that is the fuel jets should maintain their jet character and not mix too fast with the air. Reducing the number of gas spuds and increasing the momentum of the gas contribute to this effect [3].

In the present paper, the combustion characteristics of a dual swirl vanes co-axial burner are studied experimentally at the change of the injection angle and position of a gaseous fuel "LPG" in light Liquid fuel by measuring temperature at different positions of flame, exhaust smoke, and regulated gas emissions such as nitrogen oxides, carbon monoxide and unburned hydrocarbons. The aerodynamic effect of injectors in combustion is also studied.

\section{The Experimental Test Rig}

The burner used in this investigation was a swirl vanes co-axial burner is designed by JAAM. It consists of an outer cylinder shelled gaseous fuel "LPG" and liquid fuel "light diesel oil "paths. All dimension of burner are shown in Fig.11

LPG gets out from eight annular jet fingers that are supplied by gas from an annular room. The jet finger is a stainless steel tube of $1 \mathrm{~mm}$ inner diameter. Its length is $100 \mathrm{~mm}$ in order to have a maximum range to interact with the atomized liquid fuel. The jet fingers outlet ends are classified in four groups each one have a different design which let the gaseous jet gets with four angle of injection $\left(\theta=60^{\circ}, 45^{\circ}, 30^{\circ}\right.$, and $\left.0^{\circ}\right)$ as shown in Fig 1 . The light liquid fuel 
is atomized from a nozzle that is supplied by liquid fuel by a tube connected by a liquid fuel pumping system. The nozzle atomizing angle is $45^{\circ}$ with a discharge rate 0.75 .

The test rig was designed with many facilities to study the combustion characteristics. A sketch of the test is shown in Fig.2. The light liquid fuel is supplied from fuel tank (5) to the burner (3) by a pump connected to liquid supply line (6). The nozzle of angle $45^{\circ}$ is used to atomize the fuel inside the burner to fine droplets. LPG is stored in bottles which are connected with a gaseous fuel line (4). The gas pressure is controlled by a pressure regulator and its flow rate controlled by a flow-meter (9). The gas is distributed in combustion around the swirl from eight fingers (11) by a small annular gas-room of the burner. The position of the gas injection is controlled by move the gas-room with a few screws forward or backward. The air of combustion is supplied by an air blower. The exhaust gases of combustion flow out through the chimney.

The combustion air is swirled by a vanned swirl of $30^{\circ}$ vane angle which has a swirl number of 4 for this design [3].The burner is connected to a cylindrical water cooled chamber that has many ports to get samples or measuring temperature and exhaust analysis.

The temperatures of flame and hot gases $(\mathrm{T})$ at different locations along the combustion chamber in all of different cases of study were measured by a bare wire thermocouple ( $\mathrm{S}$ type) with an error of $\pm 0.1 \%$ of the reading values.

The exhaust gases are analyzed by using a gas analyzer that has different cells to determine the value of nitrogen oxides, carbon monoxide and unburned hydrocarbons.

This study was done at thermal energy of $50 \mathrm{KW}$ with $70 \%$ of this energy is generated by the combustion of light diesel fuel where $30 \%$ of thermal energy is generated by the combustion of LPG. Experiments were also carried out at constant air mass flow rate of $60 \mathrm{~kg} / \mathrm{hr}$, and constant air-fuel $(\mathrm{A} / \mathrm{F})$ ratio of 15 . The parameters of investigations were at constant percentage of injected gaseous "LPG" $(30 \%)$, with different injection locations $\left(\mathrm{X}_{\mathrm{inj}} / \mathrm{D}=0\right.$, $0.04,0.08 \ldots$ to 0.2 ) in axial direction for each injection finger group. The temperature is measured at different positions axial at distance $\left(\mathrm{X}_{\mathrm{a}} / \mathrm{D}=0.2,0.4 \ldots\right.$. to 2$)$ and at distance of $\left(R / R_{0}=0,0.04,0.8 \ldots .1\right)$ in radial measured from the center. All of distance $X_{\text {inj }}$ and $X_{a}$ are measured from the burner end. The exhaust samples are taken in the chimney.

\section{Operating Conditions}

The measurements are done under a constant value of thermal load that is $150 \mathrm{KW}$ by a ratio of $30 \%$ LPG and $70 \%$ light diesel fuel. The combustion is done at lean condition of $\lambda=1.1$.

\section{Results and Discussions}

The study was carried out to investigate the effect of LPG injection on combustion of light diesel fuel and combustion characteristics. The radial distribution of temperature along combustion chamber for jet finger of injection angle $\theta=0^{\circ}$ at $\left(X_{\mathrm{inj}} / \mathrm{D}=0.04,0.08 \ldots 2\right)$ is shown in Fig.3.The combustion has a high temperature at the injection distance range from $\mathrm{X}_{\mathrm{inj}} / \mathrm{D}=0.8$ to $\mathrm{X}_{\mathrm{inj}} / \mathrm{D}=1.2$ with a stable flame. Where Fig. 4 shows the radial distribution of temperature along combustion chamber for jet finger of injection angle $\theta=30^{\circ}$ at $\left(\mathrm{X}_{\mathrm{inj}} / \mathrm{D}=0.04,0.08 \ldots 2\right)$. In this case the temperature at the center of combustion chamber is higher than it in case of $\theta=0^{\circ}$ and the combustion has also a high temperature at the injection distance range from $\mathrm{X}_{\mathrm{inj}} / \mathrm{D}=0.8$ to $\mathrm{X}_{\mathrm{inj}} / \mathrm{D}=1.2$ with a stable flame. 
In case of jet finger of injection angle $\theta=45^{\circ}$, Fig.5 gives the radial distribution of temperature along combustion chamber at $\left(\mathrm{X}_{\mathrm{inj}} / \mathrm{D}=0.04,0.08 \ldots 2\right)$. The temperature at the center of combustion chamber is highest compared with all cases. Where the combustion has a high temperature at wide injection distance range from $X_{\text {inj }} / D=0.8$ to $X_{\text {inj }} / D=1.4$ compared with all cases.

Fig. 6 shows the radial distribution of temperature along combustion chamber at $\left(\mathrm{X}_{\mathrm{inj}} / \mathrm{D}=0.04\right.$, $0.08 \ldots 2$ ) for jet finger of injection angle $\theta=60^{\circ}$. The temperature at the center of combustion chamber is high but with unstable range and combustion has a high temperature at shortest injection distance range from $X_{\mathrm{inj}} / \mathrm{D}=1$ to $\mathrm{X}_{\mathrm{inj}} / \mathrm{D}=1.2$ compared with all cases.

Exhaust gases temperature in combustion chimney for jet finger of injection angles $\left(\theta=0^{\circ}\right.$, $30^{\circ}, 45^{\circ}$, and $60^{\circ}$ ) for different injection positions is shown in Fig.7.The injection of LPG at $\theta=0^{\circ}$ has the highest exhaust gases temperature for a long range (from $X_{\text {inj }} / D=0$ to $\mathrm{X}_{\mathrm{inj}} / \mathrm{D}=1.2$ ) where the case of $\theta=30^{\circ}$ is the highest in the rest range.

From the chimney, a sample of the exhaust gases was taken by the gas analyzer device for each case of study. $\mathrm{NO}_{\mathrm{X}}$ "ppm" in combustion chimney for jet finger of injection angles $(\theta=$ $0^{\circ}, 30^{\circ}, 45^{\circ}$, and $60^{\circ}$ ) for different injection positions is shown in Fig.8. The injection of LPG with $\theta=30^{\circ}$ has the highest value of $\mathrm{NO}_{\mathrm{X}}$ as a normal result because it has highest range temperature of combustion. Most of $\mathrm{NO}_{\mathrm{X}}$ is formed in the high combustion temperature value. The normal value of $\mathrm{NO}_{\mathrm{X}}$ for this design of combustion chamber is $180 \mathrm{ppm}$. But the important note that most of cases $\theta=0^{\circ}, 45^{\circ}$ and the $1^{\text {st }}$ range of $\theta=30^{\circ}, 60^{\circ}$ are under the value of $180 \mathrm{ppm}$ of $\mathrm{NO}_{\mathrm{X}}$.

$\mathrm{CO}_{2} \%$ in combustion chimney is measured by using the gas analyzer. The values of $\mathrm{CO}_{2} \%$ for jet finger of different injection angles $\left(\theta=0^{\circ}, 30^{\circ}, 45^{\circ}\right.$, and $\left.60^{\circ}\right)$ for different injection positions are shown in Fig.9. The jet finger of injection angle $\theta=45^{\circ}$ has the highest value of $\mathrm{CO}_{2} \%$ and the jet finger of injection angle $\theta=30^{\circ}$ has the $2^{\text {nd }}$ rank compared with all cases. Also, the important note that in all cases $\theta$ the value of $\mathrm{CO}_{2}$ is under $7 \%$.

Unburned hydrocarbons $\mathrm{C}_{X} \mathrm{H}_{X} \%$ in combustion chimney is also measured by using the gas analyzer. The values of $\mathrm{C}_{X} \mathrm{H}_{\mathrm{X}} \%$ for jet finger of different injection angles $\left(\theta=0^{\circ}, 30^{\circ}, 45^{\circ}\right.$, and $60^{\circ}$ ) for different injection positions are shown in Fig.10. The jet finger of injection angle $\theta=45^{\circ}$ and the jet finger of injection angle $\theta=30^{\circ}$ has high value of $\mathrm{C}_{X} \mathrm{H}_{\mathrm{X}} \%$ for the range (from $X_{\text {inj }} / D=0$ to $X_{\text {inj }} / \mathrm{D}=1.2$ ).

\section{Conclusion}

The investigation the effect of LPG injection in combustion of light diesel fuel and combustion characteristics can be concluded to:

1. The injection of LPG in combustion of light diesel fuel causes increasing of the exhaust gases in all cases of study.

2. The injection distance range from $X_{\text {inj }} / D=0.8$ to $X_{\mathrm{inj}} / D=1.2$ has the high gas and flame temperature.

3. The aerodynamic design of gaseous fuel injector affects the combustion characteristics the liquid fuel combustion.

4. The value of $\mathrm{NO}_{\mathrm{x}}$ has low value except the case of injection angle $\theta=0^{\circ}, 45^{\circ}$.

5. The best design for this type of dual co-axial burner should be with jet finger with end of inclination angle $\theta=45^{\circ}$. 


\section{References}

[1] Emara, A., Lacarelle, A., Paschereit, C. O., "Pilot Flame Impact on Flow Fields and Combustion Performances in a Swirl inducing Burner", AIAA 2009-5015, August 2009, Denver, Colorado, USA.

[2] Ahmed, M. E. Abdel-Latif,"An experimental investigation of fluid flow and combustion characteristics of dual-fuel in a cylindrical combustion chamber", Journal of Loss Prevention in the Process Industries 13 (2000) 477-490

[3] G. Colson, F. Peeters, J. De Ruyck," Experimental in-flame study of a $15 \mathrm{MW}$ dual fuel gas/oil burner", Fuel 78 (1999) 1253-1261

[4] János Miklós Beér, N. A. Chigier, "Combustion aerodynamicsFuel and energyscience series ", Virginia Unversity, Krieger,1972

[5] Vi't Kermes , Petr Be lohradsky', Jaroslav Oral , Petr Stehlı'k,"Testing of gas and liquid fuel burners for power and process industries", Energy 33 (2008) 1551-1561

[6] Ebrahim Moussavi Torshizi , Ehsan Allah Saadati ,Ali Rafiee,"Optimization of Gas Nozzles Geometry in Dual-Fuel Burnersof Power Stations",J Fail. Anal. and Preven. (2008) 8:362-369 


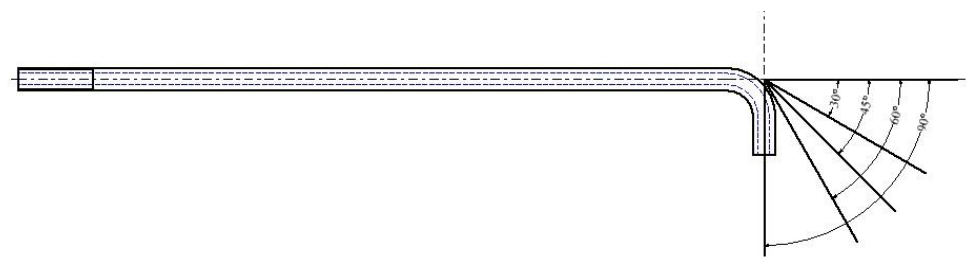

Fig 1.The gaseous jet fingers groups with four injection angles $\left(\theta=60^{\circ}, 45^{\circ}, 30^{\circ}, 0^{\circ}\right)$

\begin{tabular}{|c|l|}
\hline \multicolumn{2}{|c|}{ Description } \\
\hline 1 & Exhaust pipe \\
\hline 2 & Combustor \\
\hline 3 & JAAM burner \\
\hline 4 & Gas fuel line \\
\hline 5 & Liquid Fuel Tank \\
\hline 6 & Liquid Fuel line \\
\hline 7 & Air supply line \\
\hline 8 & Water supply line \\
\hline 9 & Flow meter \\
\hline 10 & Drain line \\
\hline 11 & Gas injector limbs \\
\hline & \\
&
\end{tabular}
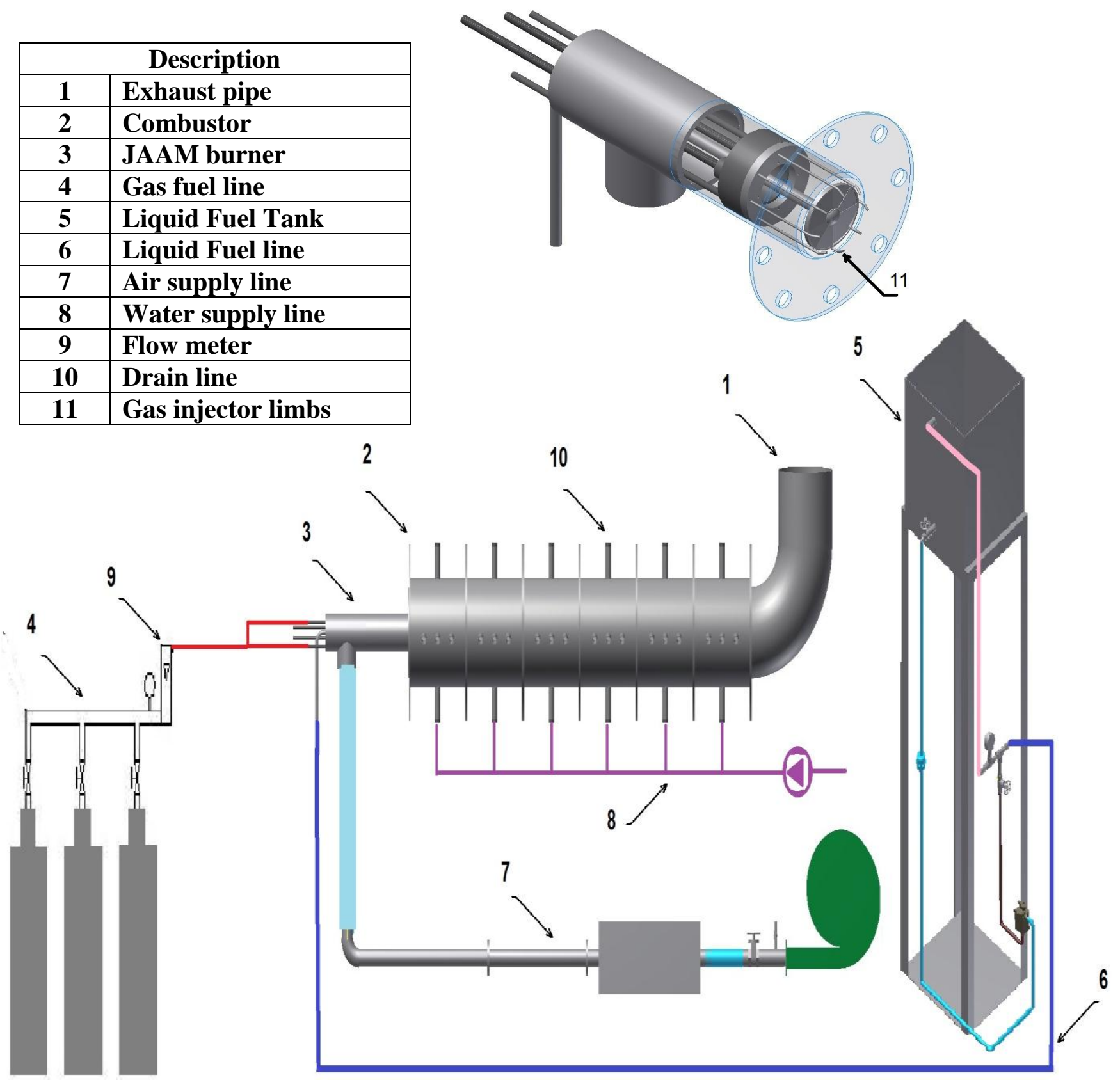

Fig.2. Schematic diagram of the test rig 

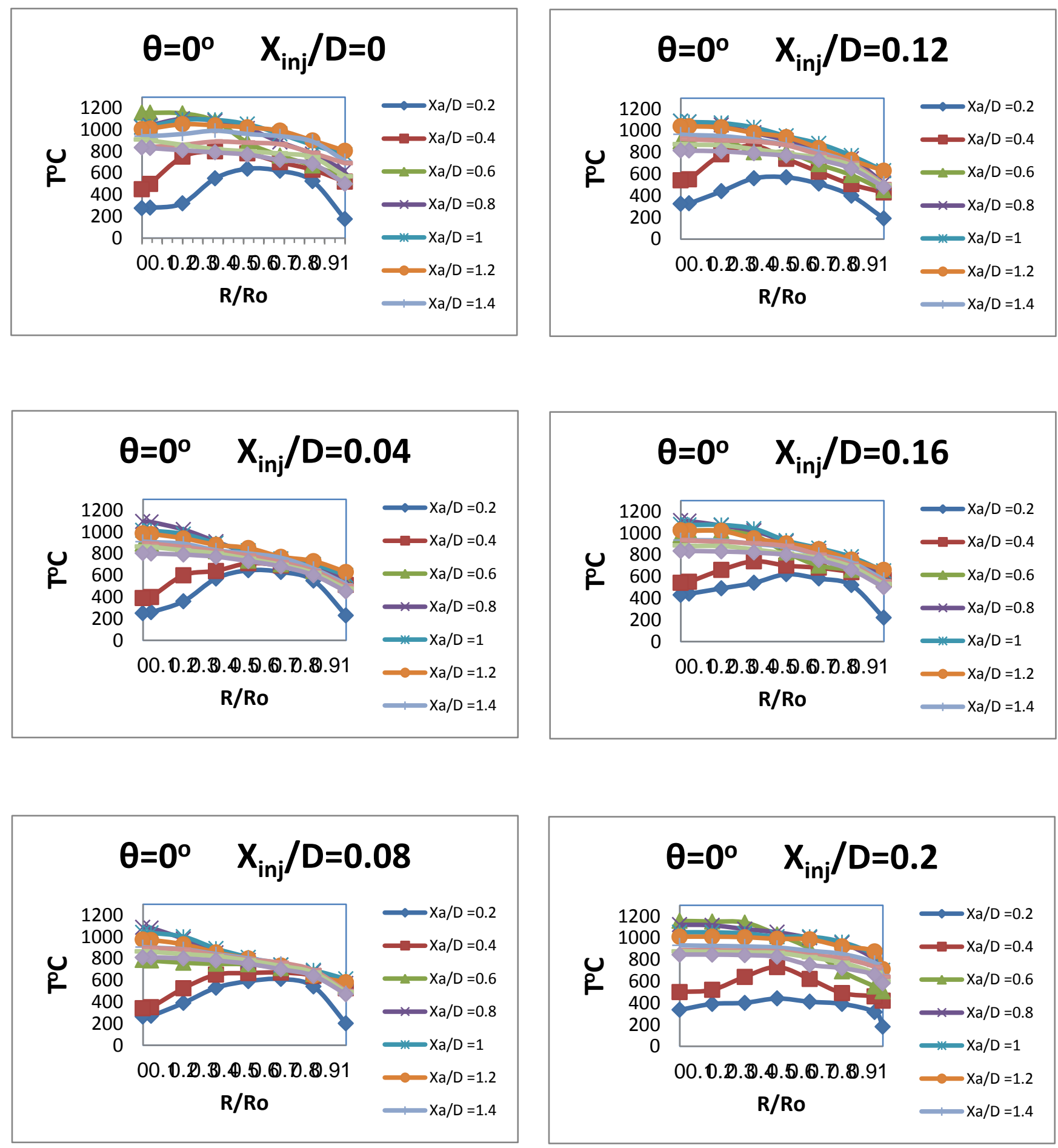

Fig.3. Radial distribution of temperature along combustion chamber for jet finger of injection angle $\theta=0^{\circ}$ at $\left(X_{\mathrm{inj}} / \mathrm{D}=0.04,0.08 \ldots 2\right)$. 

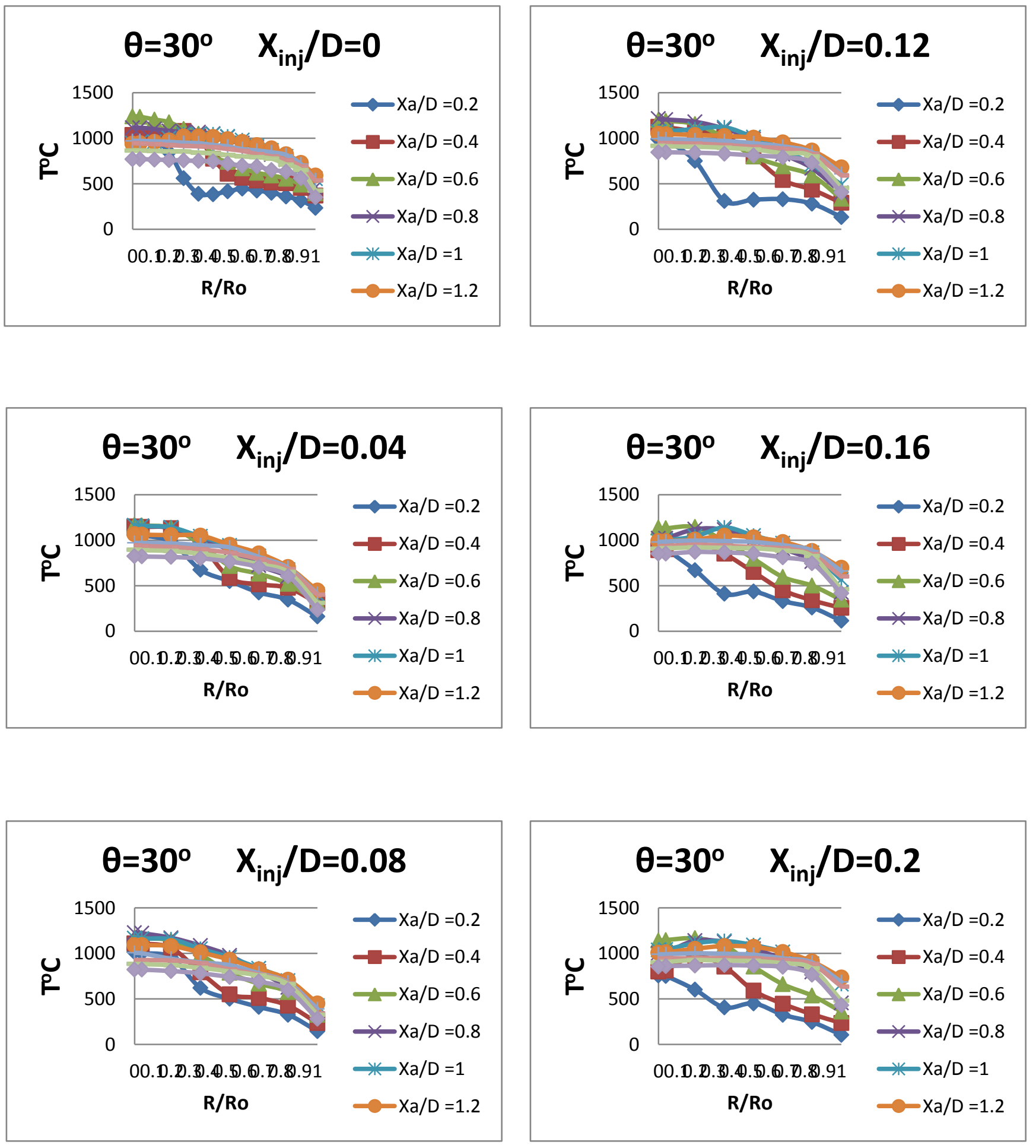

Fig.4. Radial distribution of temperature along combustion chamber for jet finger of injection angle $\theta=30^{\circ}$ at $\left(X_{\text {inj }} / D=0.04,0.08 \ldots 2\right)$. 

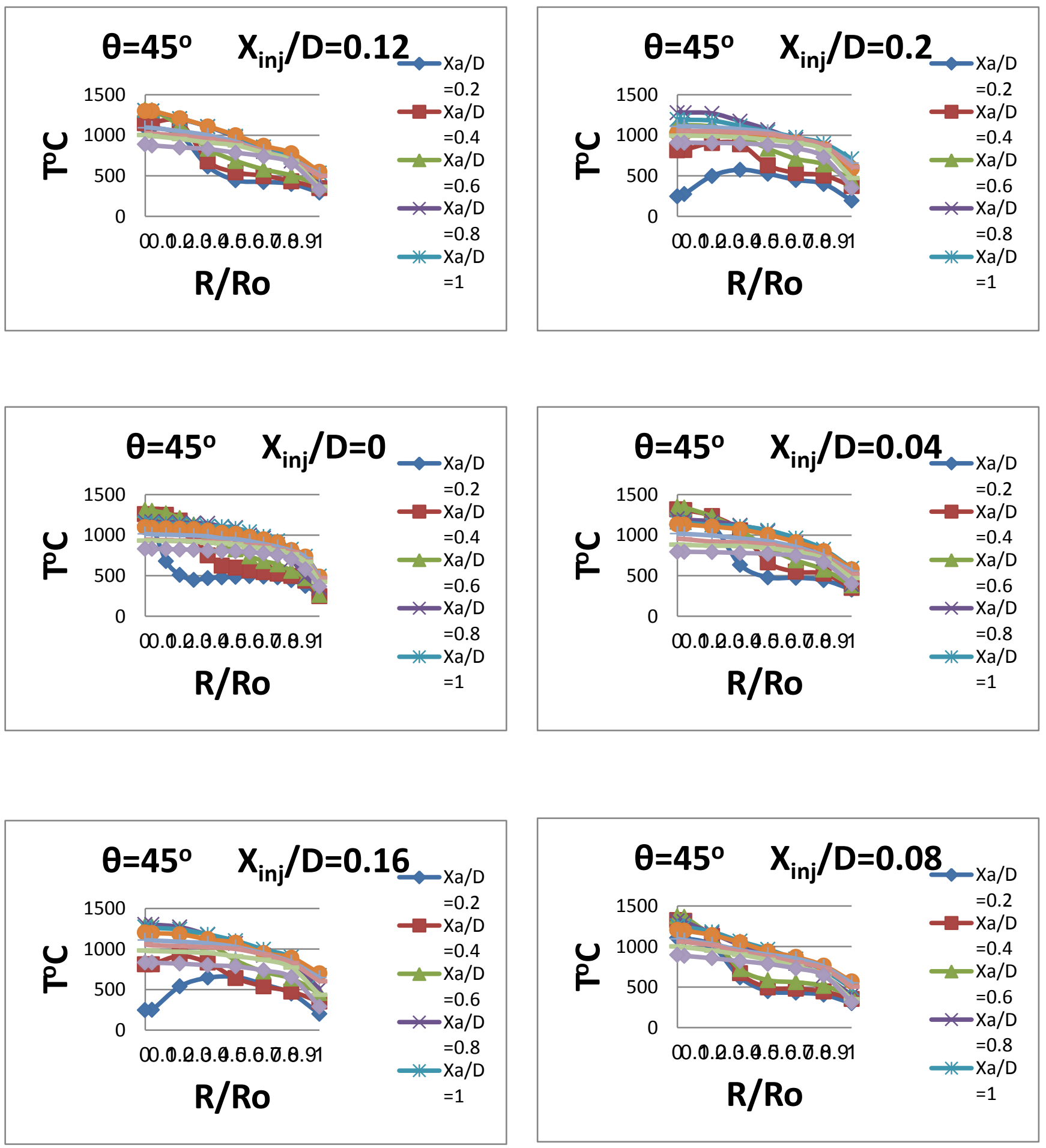

Fig.5. Radial distribution of temperature along combustion chamber for jet finger of injection angle $\theta=45^{\circ}$ at $\left(X_{\mathrm{inj}} / \mathrm{D}=0.04,0.08 \ldots 2\right)$. 

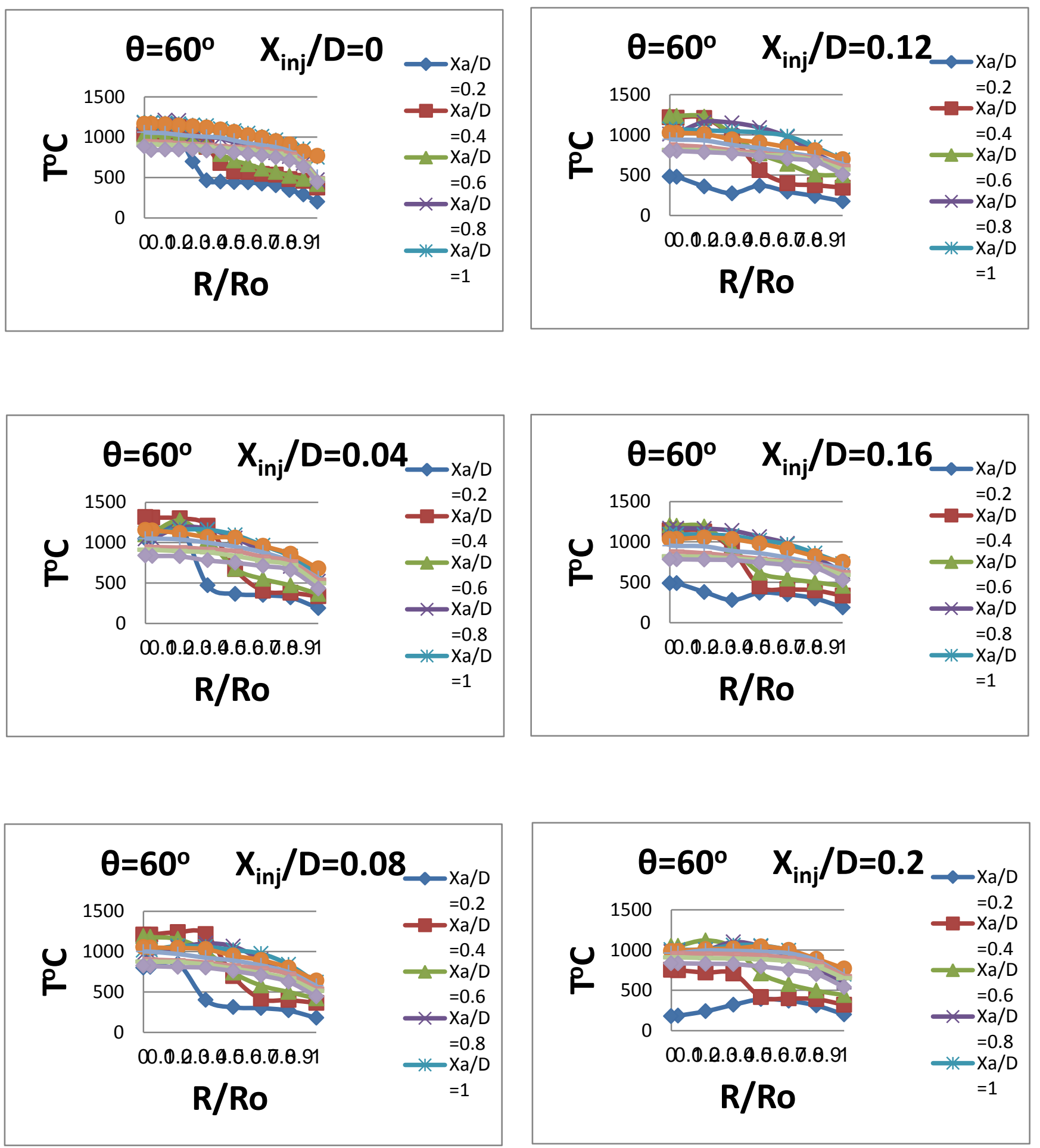

Fig.6. Radial distribution of temperature along combustion chamber for jet finger of injection angle $\theta=60^{\circ}$ at $\left(X_{\mathrm{inj}} / \mathrm{D}=0.04,0.08 \ldots 2\right)$. 


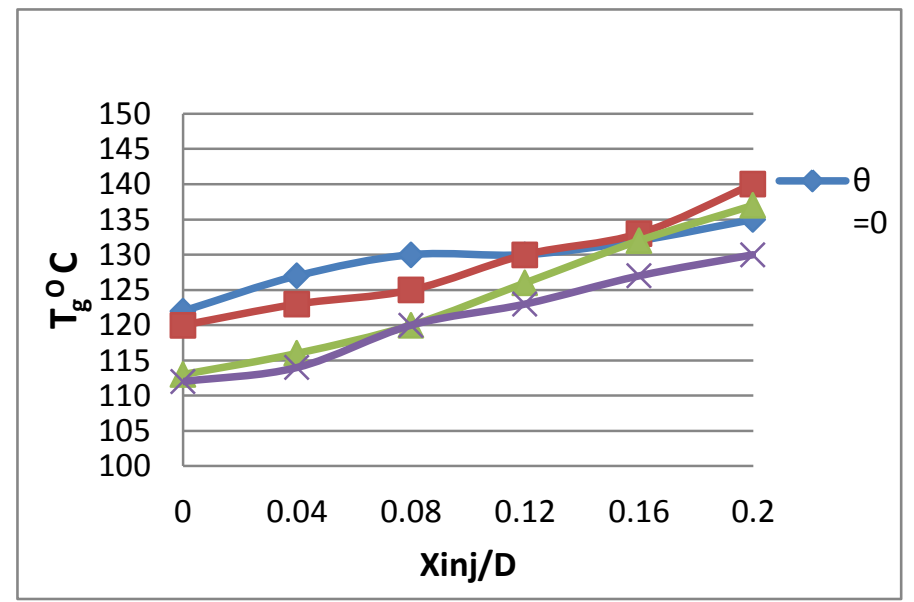

Fig.7. Exhaust gases temperature in combustion chimney for jet finger of injection angles $\left(\theta=0^{\circ}, 30^{\circ}, 45^{\circ}\right.$, and $\left.60^{\circ}\right)$ for different injection positions

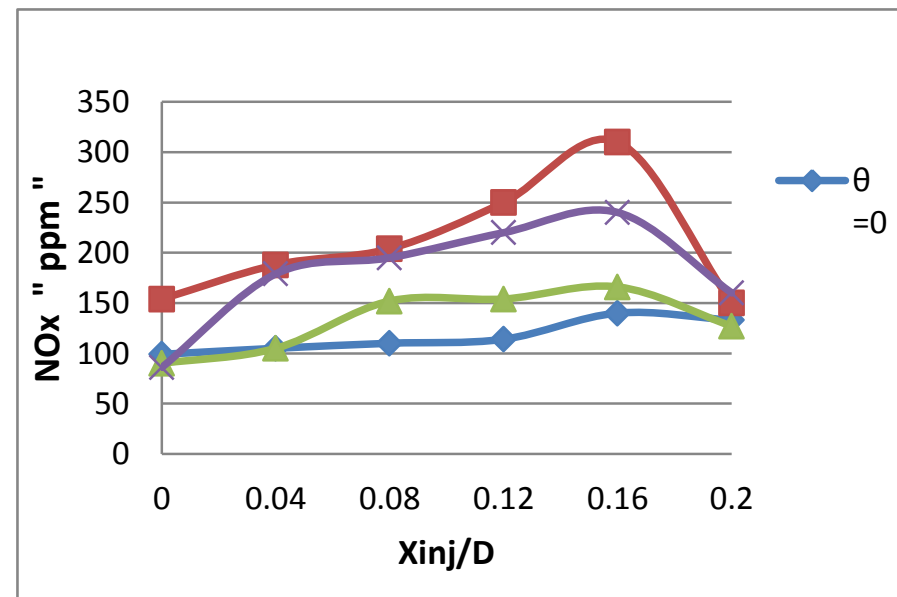

Fig.8. $\mathrm{NO}_{\mathbf{x}}$ "ppm" in combustion chimney for jet finger of injection angles $\left(\theta=0^{\circ}, 30^{\circ}, 45^{\circ}\right.$, and $\left.60^{\circ}\right)$ for different injection positions 




Fig.9. $\mathrm{CO}_{2} \%$ in combustion chimney for jet finger of injection angles $\left(\theta=0^{\circ}, 30^{\circ}, 45^{\circ}\right.$, and $\left.60^{\circ}\right)$ for different injection positions

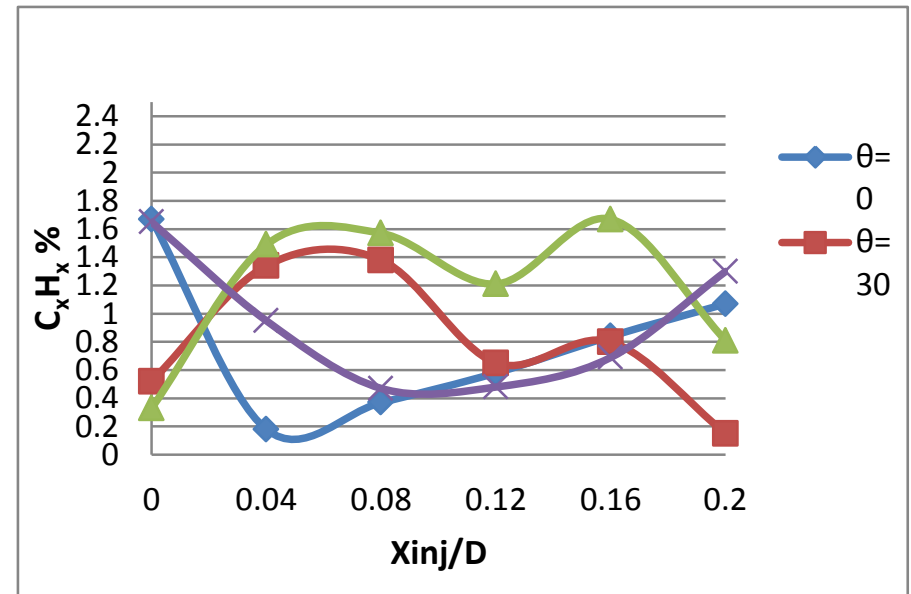

Fig.10. $\mathrm{C}_{\mathbf{X}} \mathrm{H}_{\mathbf{X}} \%$ in combustion chimney for jet finger of injection angles $\left(\theta=0^{\circ}, 30^{\circ}, 45^{\circ}\right.$, and $\left.60^{\circ}\right)$ for different injection positions 

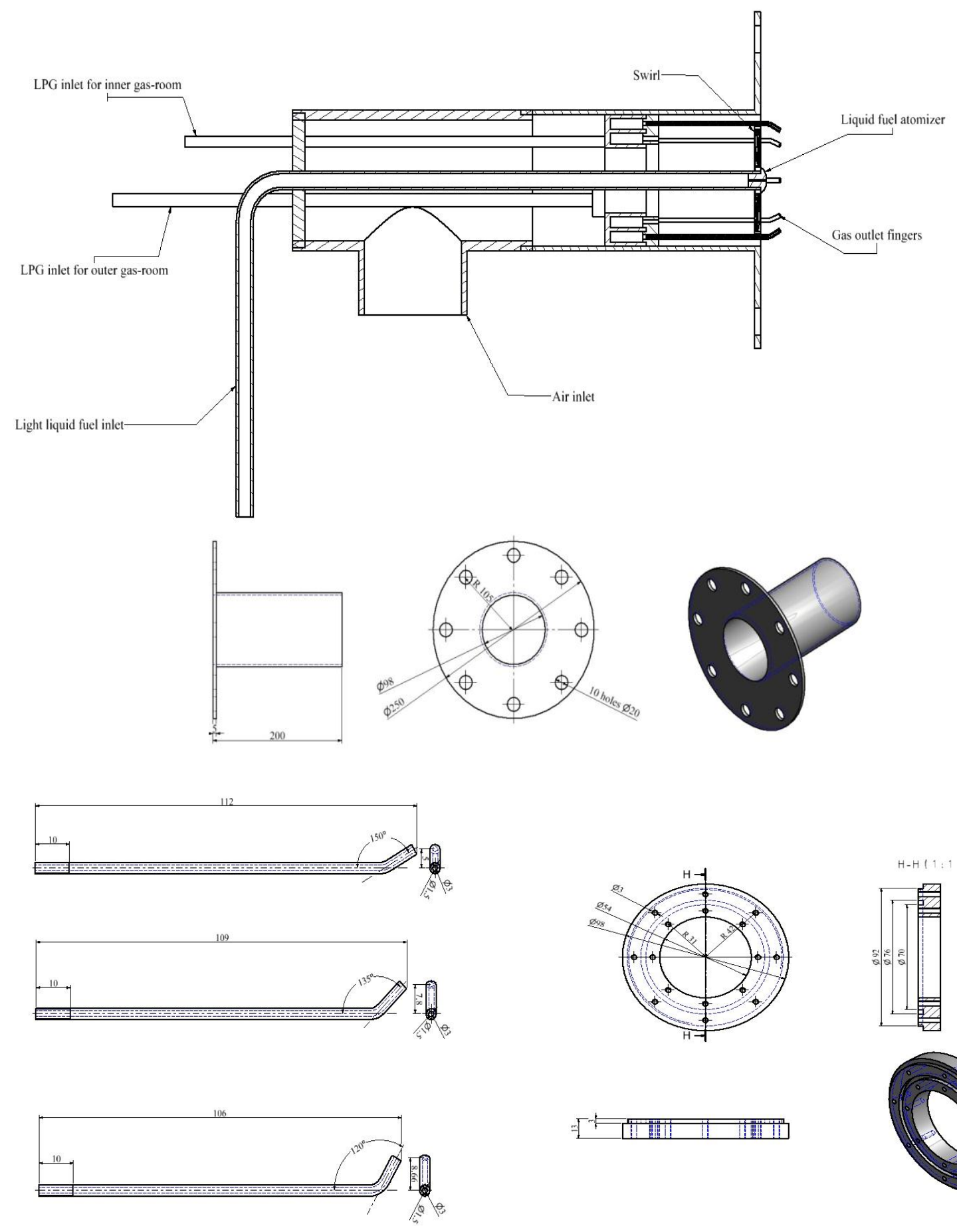

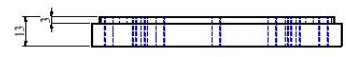

Fig.10. Burner dimensions 